\title{
ALBERTO RUZ LHUILLIER MÁS ALLÁ DEL DESCUBRIMIENTO DE LA TUMBA DEL TEMPLO DE LAS INSCRIPCIONES DE PALENQUE. MILITANCIA POLÍTICA Y ARQUEOLOGÍA MAYA
}

\author{
Ana LUISA IZQuiERdo y DE LA CUEVA \\ Centro de Estudios Mayas, Instituto de Investigaciones Filológicas, \\ Universidad Nacional Autónoma de México \\ Elaine Day Schele \\ Adjunct Assistant Professor, Austin Community College
}

\begin{abstract}
RESUMEN: Este artículo desarrolla tres temas: el primero es la militancia política de Alberto Ruz contra los gobiernos cubanos títeres apoyados por los Estados Unidos, el segundo son sus aportaciones a la arqueología científica mexicana, que fueron más allá del magno descubrimiento de la tumba de K'inich Janaab' Pakal de Palenque, y el tercero, su defensa del patrimonio arqueológico nacional.

El segundo, más ampliamente desarrollado, aborda tanto las ideas capitales que guiaron su trabajo académico, como el marco teórico-metodológico que aplicó. Asimismo se describen las polémicas en las que participó, dejando fuera sus excavaciones en Palenque. En la última parte del artículo se relata lo concerniente a sus luchas por proteger y dar nueva vida y vigencia al patrimonio arqueológico maya.

Palabras Clave: Alberto Ruz, cultura maya, arqueología mexicana, patrimonio arqueológico, Cuba.
\end{abstract}

ABSTRACT: This article is about Alberto Ruz, the archaeologist who made the remarkable discovery of the tomb of K'inich Janaab' Pakal of Palenque, however it is not about his archaeological discoveries. Instead the article has three themes: the first is Alberto Ruz's political activism against the US puppet governments of Cuba; the second is his contributions to the science of Mexican archaeology; and the third is about his defense of Mexico's archaeological heritage.

More specifically, the themes are explored and developed by detailing Ruz's most important ideas that guided his academic work. We outline the theoretical and methodological frameworks he applied and the political struggles in which he participated. We also describe his courageous efforts to protect and to give new life and strength to Maya archaeological heritage.

KeYwords: Alberto Ruz, Maya culture, Mexican archaeology, archaeological heritage, Cuba.

RECEPCIÓN: 5 de febrero de 2015.

ACEPTACIÓn: 24 de abril de 2015. 


\title{
ALBERTO RUZ LHUILLIER MÁS ALLÁ DEL DESCUBRIMIENTO DE LA TUMBA DEL TEMPLO DE LAS INSCRIPCIONES DE PALENQUE. MILITANCIA POLÍTICA Y ARQUEOLOGÍA MAYA
}

\author{
Ana Luisa IzQuierdo y de la Cueva \\ Centro de Estudios Mayas, Instituto de Investigaciones Filológicas, \\ Universidad Nacional Autónoma de México \\ Elaine Day Schele \\ Adjunct Assistant Professor, Austin Community College
}

Cada hombre trae en sí el deber de añadir, de domar, de revelar. Son culpables las vidas empleadas en la repetición cómoda de las verdades descubiertas.

José Martí

Para recordar al mayista Alberto Ruz Lhuillier, personaje raíz de la arqueología científica mexicana, no sólo se debe traer a la memoria su magno descubrimiento, el domingo 15 junio de 1952, de la tumba de K'inich Janaab' Pakal en el Templo de las Inscripciones de Palenque, que fue, sin duda, un hallazgo fundamental en el desarrollo de la arqueología maya y un avance significativo para comprender su pensamiento religioso, así como sus costumbres funerarias, por tratarse de un conjunto arquitectónico, escultórico y funerario único. Tal hecho abarca una intensa y reveladora parte de su obra académica, pero es sólo un capítulo en el valioso legado de Ruz para contribuir al conocimiento que hoy tenemos de la civilización maya (figura 1). ${ }^{1}$

El distinguido arqueólogo nació el 27 de enero de 1906 en París, hijo del cubano Francisco Alberto Ruz y Mas, y de la francesa Louise Lhuillier, originaria de la región de Bordeaux. De niño, Alberto asistió al colegio Carnot, en el barrio de Colombes, y al terminar, entre 1921 y 1923, estudió comercio (Ruz, 1979a). Creció

\footnotetext{
${ }^{1}$ Hasta ahora el estudio más completo de este hallazgo ha sido hecho por la coautora de este artículo, Elaine Day Schele, en su tesis de doctorado, presentada en la Universidad de Texas en Austin en 2012.
} 


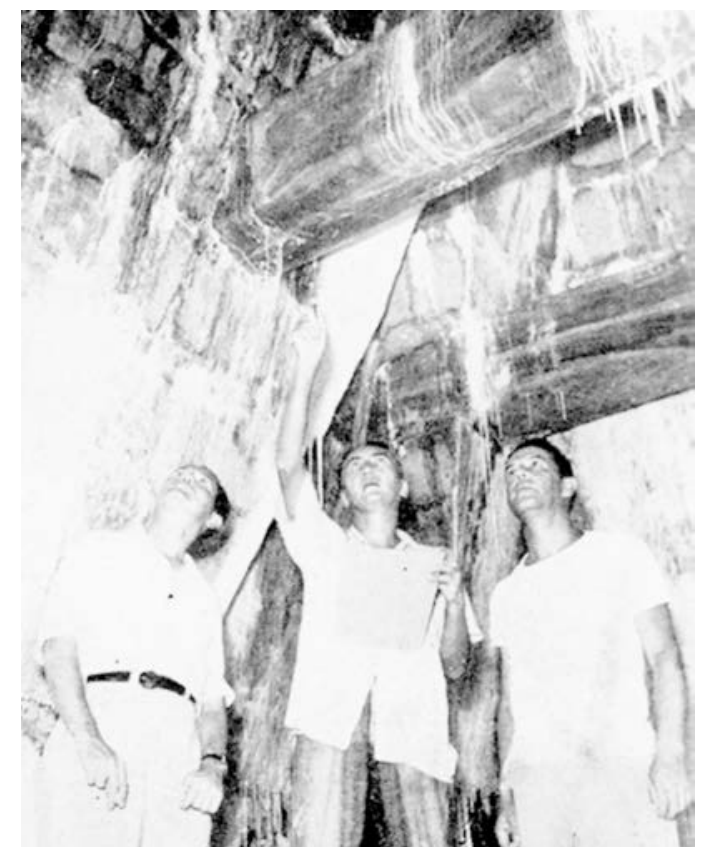

Figura 1. Ingreso de la Cámara del Templo de las Inscripciones de Palenque. Jorge Angulo a la derecha, Arturo Romano a la izquierda y al centro Alberto Ruz. Publicada por la revista Life en 1953: 73.

con sus padres en la Avenida Wagram, en un vecindario de exilados cubanos que habían huido al inicio de la guerra de Independencia de Cuba (Estrade, 2001: 409).

El primero que llegó a París fue su abuelo, Francisco Ruz Amores, un terrateniente que destacó al ser el primero en dar libertad a los esclavos que tenía en su finca (Izquierdo, 1987: 11), a más de haber combatido en la "Guerra de los Diez Años" (1868-1878), primera lucha de independencia de Cuba contra la metrópoli española. Don Francisco pertenecía a un grupo de intelectuales y ricos aristócratas de la isla que emigró a París en busca de tranquilidad y oferta cultural. Cuando Alberto nació, su familia tenía más de 30 años de vivir en Francia. Sin embargo, su padre fomentó en él, como en sus otros hijos, Suzanne, Lily y Miguel (Estrade, 2001: 332) la identidad, el nacionalismo y el amor a Cuba, pero sobre todo les hizo conscientes de los cambios políticos que sufría su país, y recalcándoles la ambición de los Estados Unidos por dominar la isla.

Su abuelo y su padre habían sido testigos de la firma en París de la independencia de Cuba de España (1898), ${ }^{2}$ y dos años después, al presentarse la Enmienda

\footnotetext{
${ }^{2}$ En el Congreso de los Estados Unidos quedó consignada la firma de la independencia de Cuba, exigiendo que el gobierno de España renunciara a su autoridad y gobierno sobre la isla, y retirara
} 
Platt a la Constitución cubana (del 26 de febrero de 1901), de la inauguración de la época del protectorado estadounidense en la isla y su consignación en el derecho internacional. Por ello, su padre editó, en francés, más de 30 artículos en el periódico de la comunidad en el exilio: la République Cubaine (Estrade, 2001: 410). Alberto procedía, pues, de una familia con inquietudes humanistas y lúcidos escritores, y heredó de su padre la disciplina y el talento para escribir.

Cumplidos los 20 años, el joven Alberto salió de París con rumbo a Cuba, a fin de intentar rescatar algunas posesiones familiares, aprender español y estudiar la preparatoria para ingresar a la Universidad de la Habana y seguir la carrera de ingeniería azucarera (Ruz, 1979a). Llegó a la isla en un momento de agitación política que duraría por lo menos 30 años más. El general Gerardo Machado Morales se había convertido en presidente en mayo de 1925, con el apoyo del gobierno de Estados Unidos y de los magnates del imperio azucarero del que dependía prioritariamente la economía de Cuba. Con el tiempo se convirtió en un dictador cada vez más opresivo (Argenteri, 2003: 105).

La represión y una crisis económica originada por los estadounidenses produjeron la movilización social, principalmente estudiantil, que se articuló en el "Directorio Estudiantil Universitario" (Leuchsenring, 1979: 252). Ruz comenzó a trabajar en ese grupo y se acercó a sus líderes, principalmente a Antonio Guiteras Holmes, a quien se ha considerado el antecesor ideológico de Fidel Castro. Fue en el movimiento del "Directorio..." donde Alberto conoció a Calixta, hermana de Antonio, con quien contrajo matrimonio y se integró a la familia Guiteras, viviendo en una comunidad dedicada a la lucha política.

Ambos compartían historias similares: habían nacido en el extranjero, sus padres eran cubanos comprometidos con la lucha por la absoluta autonomía de Cuba y habían abrevado de las ideas socialistas de sus progenitores, además de compartir una cuidadosa educación en la cultura universal. Se manifestaban, hacían panfletos, reunían armas y conspiraban. Fueron repetidamente perseguidos y encarcelados con otros activistas. A Calixta la procesaron por haber participado en un plan para ejecutar al dictador Machado y fue sentenciada a ocho años de prisión. Recordaría años después cómo, al vivir con su familia, Ruz apoyaba sus ideales (Tabares del Real, 1973: 123, 424). La excarcelaron por padecer una enfermedad pulmonar, y la primera opción de la pareja fue irse a París donde permanecieron un año de 1932 a 1933, quizás al abrigo de la madre de él.

Durante su ausencia, Machado renunció y Estados Unidos instaló un presidente títere: Carlos Manuel de Céspedes (Suchlicki, 1968: 363), pero Fulgencio Batista lo destituyó e integró en su lugar un Comité Ejecutivo, conformado por el doctor Ramón Grau San Martín, que representaba el reformismo moderado;

sus fuerzas terrestres y marítimas del territorio isleño y sus aguas, y ordenaba al presidente de los Estados Unidos hacer uso de las fuerzas de tierra y mar en caso necesario, autorizándolo para dejar el gobierno y control de la isla a los cubanos tan pronto como se hubiera establecido un gobierno bajo una Constitución (Leuchsenring, 1973: 22). 
Antonio Guiteras Holmes, de tendencias socialistas radicales, y Fulgencio Batista Zaldívar, situado a la derecha, al frente del Ejército. Alberto y Calixta se enteraron de las noticias del ascenso al Poder Ejecutivo cubano de su cuñado y hermano, respectivamente, en el barco en el que regresaban de Francia (Tabares del Real, op. cit.: 128).

Al llegar a Cuba en septiembre de 1933, Ruz recibió el cargo de director de Asuntos Municipales, así como de director de Cultura y Bellas Artes, por parte de su cuñado Guiteras, quien en ese momento era Secretario del Interior (Hilton, 1945: 108-109). Este gobierno fue depuesto a los 100 días y los funcionarios públicos perseguidos. La pareja de Alberto y Calixta continuó trabajando con los opositores al gobierno, ya durante el régimen de Fulgencio Batista (Ruz Buenfil, 2010). Volvieron a caer en prisión. Al parecer, Ruz llegó a la cárcel a causa de haber escrito en la revista Mundo Infantil un reportaje sobre el barrio deprimido de Las Yaguas, por el que fue sentenciado a seis años de prisión (Izquierdo, 1987: 11). Estando encarcelados supieron del asesinato de Antonio Guiteras.

El gobierno les dio la opción de exiliarse o seguir sujetos a la persecución. Debido a los problemas de salud de Calixta decidieron buscar refugio en México (1935), donde tomaba la presidencia de la República Lázaro Cárdenas, el único presidente socialista que ha tenido el país, y que abrió las puertas a todos los refugiados políticos, tanto a los republicanos españoles como a los judíos. La política mexicana era totalmente compatible con los ideales de la pareja en cuanto a derechos, libertades y redención de los desposeídos, y decididamente antiestadounidense, a más de que seguían los pasos de Martí, quien también buscó protección en México (1875-1877). De inmediato el joven matrimonio se enamoró de su país de refugio, en especial de sus facetas indígenas, y decidió conocerlo a fondo. Ambos optaron por estudiar antropología y dedicarse a la academia; mientras tanto, vivían de dar clases, de inglés ella, y de francés él. En cuanto se fundó la carrera de Antropología en el Instituto Politécnico Nacional (1938), los dos se inscribieron. Él contaba ya con 32 años (Ruz, Dirección General de Personal, 1979).

Desde ese momento, aunque ya separados, Alberto y Calixta se entregaron totalmente a la academia, apartándose de la lucha política, a tal grado que no participaron en la construcción fáctica e ideológica de la Revolución cubana que se gestó en México. Tampoco tuvieron contacto con Fidel Castro Ruz, con quien, al parecer, no unían a Alberto lazos de parentesco. ${ }^{3}$ No obstante, Ruz desarrolló una

\footnotetext{
${ }^{3}$ Michael Coe (1992: 208) afirma maliciosamente que Ruz Lhuillier y los Castro Ruz eran parientes; asimismo hay otras voces que recuerdan que durante la estancia de Alberto en París (1973-1974) comentaba de sus primos los Castro y narraba que con quien había tenido ligas era con Raúl. Sin embargo, en el Centro de Estudios Mayas del IIFL de la UNAM siempre afirmó que los Castro no eran sus familiares. Por otro lado, mientras Ruz era de una familia de terratenientes ricos e intelectuales, la madre de Fidel y Raúl, Lina Ruz, era mujer sin recursos económicos ni estudios. Además, durante la estancia de Ruz en Cuba (1926-1935), Fidel acababa de nacer (1926) y Raúl nacería en 1931, por lo que difícilmente pudieron haber tenido contacto. Asimismo, cuando Fidel y Raúl estuvieron exiliados en México (1956), Ruz ya había descubierto la tumba de K’inich Janaab' Pakal de Palenque y gozado del financiamiento para las excavaciones de Palenque del potentado estadounidense Nelson Rockefeller
} 
discreta participación política con los intelectuales exilados y, como todos ellos, se unió a la "Liga de Escritores y Artistas Revolucionarios" (LEAR), que se consideraban abogados de la clase trabajadora, luchadores contra el fascismo en el mundo, y en general críticos del statu quo, principalmente en México (Caplow, 2007: 93).

Don Alberto optó por la nacionalidad mexicana en 1940 (Ruz, 1979a) y tanto él como Guiteras se relacionaron y vincularon con el pueblo estadounidense por medio de la vida académica, él principalmente con sus colegas arqueólogos, con los que se vinculó estrechamente. Así por ejemplo, cultivó una entrañable amistad con Edward Wyllys Andrews IV (1916-1971) (Ruz, 1973c: 381), así como lazos académicos y filiales con Sylvanus Morley, Herbert J. Spinden, Alfred V. Kidder (Ruz, 1961: 7), Georges Stuart, Evon Z. Vogt, George Kubler, Gordon Willey, Bárbara y Robert Rands y Michael Coe (Vogt y Ruz, 1964). Por otro lado, aceptó realizar las excavaciones de Palenque impulsado por Ignacio Marquina, a la sazón director del Instituto Nacional de Antropología e Historia (1943-1956), con los financiamientos de Nelson Rockefeller a través del Instituto de Estudios Andinos del Museo de Historia Natural de Nueva York (1947) y trabó buena relación con dicho mecenas; tanto, que acudió a él en busca de fondos para eventos y fundar nuevas instituciones de investigación más de una década después (figura 2).

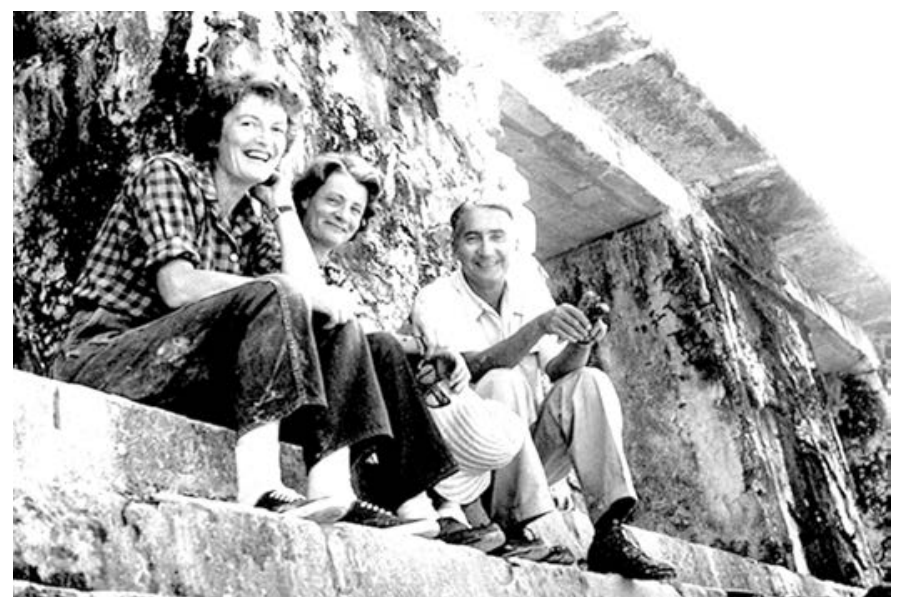

Figura 2. Alberto Ruz con la señora Mary Todhunter Clark de Rockefeller y otra dama no identificada. Archivo Miguel Covarrubias, Universidad de las Américas, Dirección General de Bibliotecas, Arquitectura Maya I (Dibujos, Fotografías y Recortes). Fotografía de Rosa Covarrubias.

Calixta, por su parte, se volvió una famosa etnóloga, desarrolló lazos con los profesionales de la antropología estadounidense, principalmente con Robert Redfield, y llegó a ser investigadora (research fellow, 1956-60) en la Universidad de

y recibió otros montos pequeños de Howard Leichner (1954-1955) y Ms. Bullington (1956) (Elaine Schele, 2012: 246, 249). 
Chicago, donde escribiría su más famoso libro: Perils of the Soul. The World View of a Tzotzil Indian (1961), editado en español en 1965 con el título Los peligros del alma. Visión del mundo de un tzotzil.

Como arqueólogo, Ruz se desempeñó en dos ámbitos académicos: primero adscrito al Instituto Nacional de Antropología e Historia (1940-1960), y después a la Facultad de Filosofía y Letras de la Universidad Nacional Autónoma de México desde 1959 hasta 1979, año de su fallecimiento. En esa institución obtuvo el grado de doctor en Antropología en 1965. Sin embargo, regresó al INAH, comisionado por la UNAM, como director del Museo Nacional de Antropología, al que dirigió de enero de 1977 a agosto de 1979 (Ruz, 1979a).

Desde que Ruz ingresó al INAH destacó en la construcción de los cimientos de la arqueología científica mexicana, con los marcos metodológicos en boga en los ámbitos internacionales del conocimiento de la disciplina, como la antropología cultural de Franz Boas, y otros más que en el transcurso de su trabajo académico fueron surgiendo, siendo él, en México, el iniciador de algunos de ellos. Asimismo cabe enfatizar que fue el primer arqueólogo mayista mexicano, al tiempo que numerosos estadounidenses trabajaban en el área maya, como Gordon Randolph Willey, Eduard Wyllys Andrews, Karl Ruppert, Robert Wauchope, Samuel Kirkland Lothrop, entre otros (Schele, 2012: 40).

Conviene recordar que Alberto Ruz no comenzó su carrera académica estudiando la cultura maya, sino que primero fue ayudante de Alfonso Caso en Monte Albán, después trabajó en la clasificación de la cerámica del mismo sitio y en el análisis de los códices mixtecos (Ruz, 1973: 365). Inició luego una tesis sobre los "Horizontes estratigráficos en La Quemada, Chalchihuites y el Zape, en Zacatecas", en la cual no avanzó (Ruz, 1942). En sus propias palabras, fue Caso el que definió su vocación para la arqueología y quien lo condujo por el camino de los estudios mayas (Ruz, 1973a: 365).

En 1943 fue nombrado director de Investigaciones Arqueológicas en Campeche, por el mismo Caso, lo que implicó cambiar de área de investigación y estudiar la arqueología del litoral campechano, cuyo resultado fue la tesis "La costa de Campeche en los tiempos prehispánicos. Prospección cerámica y bosquejo histórico", presentada en 1945 con la colaboración de su entonces esposa Blanca Buenfil Blengio. Contó con el apoyo y financiamiento de los gobernadores de Campeche Héctor Pérez Martínez y Eduardo Lavalle Urbina. La ayuda económica del primero fue ilimitada. Se trataba de un político de primer rango en México, pero además de un investigador nato de la cultura maya, que produjo la primera edición en español de la Relación de las cosas de Yucatán de fray Diego de Landa y publicó un Catálogo de documentos para la historia de Yucatán y Campeche. ${ }^{4}$

\footnotetext{
${ }^{4}$ Fray Diego de Landa, Relación de las cosas de Yucatán, Héctor Pérez Martínez (introd., notas y ed.). México: Editorial Robredo, 1938, y Héctor Pérez Martínez, Catálogo de documentos para la historia de Yucatán y Campeche, que se hallan en diversos archivos y bibliotecas de México y del extranjero. Campeche: Museo Arqueológico, Histórico y Etnográfico de Campeche, 1943.
} 
La Costa de Campeche en los tiempos prehispánicos (publicada en 1969) fue piedra angular de su carrera académica, ya que en ella plasma el método que va a seguir en sus estudios; asimismo, porque demuestra el cuidadoso cientificismo de sus investigaciones y la originalidad de aplicar en México enfoques nuevos que apenas comenzaban a estar en boga en la arqueología estadounidense. De esta manera practica el trabajo de campo con planeación y cuidado: ubica asentamientos y los registra en la cartografía del litoral, hace mapas de los sitios y planos de los edificios; recoge cerámica que compara con las colecciones privadas y con acervos de museos de la península de Yucatán, así como de los muestrarios de las excavaciones emprendidas por la Carnegie Institution de Washington, principalmente de Wyllys Andrews en el suroeste de Campeche y Tabasco en México, y el Petén en Guatemala (Ruz, 1969). Formalizó, entonces, el primer trabajo de prospección cerámica por área en el territorio nacional realizado por un mexicano. La Costa de Campeche en los tiempos prehispánicos debe considerarse como un ensayo empírico con la perspectiva que estaba surgiendo en esos momentos y que extiende sus principios teórico-metodológicos hasta ocho años después con los trabajos de Gordon Willey, quien propuso los principios del llamado "patrón de asentamiento" (1956).

En esta obra ensayó otro nuevo y original enfoque en México: emitir opiniones, con base en la arqueología, de lo que en ese momento se llamaba la ecología humana, es decir, cómo el medio ambiente condicionaba los cambios culturales. Así, puntualizó que en la costa de Campeche el comercio había sido una actividad central y el tráfico acuático de bienes materiales una labor cotidiana (Ruz, 1969: 29), todo ello derivado de las características del medio geográfico. De esta manera se vinculaba a la corriente de la ecología cultural que se comenzaba a formar en los Estados Unidos encabezada por Julian Haynes Steward.

Un rasgo relevante de su método de trabajo fue tratar de armonizar los datos plasmados en las fuentes históricas y los de la arqueología, es decir, realizar ejercicios multidisciplinarios; el libro sobre Campeche fue el primero de muchos otros en los que seguiría este camino. Su proyecto de la costa campechana lo elaboró a partir de lo que asientan los testimonios coloniales de cronistas y frailes, así como del textos mayas escritos en caracteres latinos como los Chilames, y cualquier otro texto que se hubiera referido a ese territorio en la época prehispánica o colonial; también añadió información etnográfica de la zona. Así, excavaría en El Aguacatal, el rancho Xicalango, Guarixés en Isla del Carmen, Tixchel, Champotón, Jaina y la ciudad de Campeche.

La seriación cerámica que desarrolló Ruz colocaba la primera época en el horizonte que él llamó arcaico-olmeca-premaya, ubicándolo en Tixchel y Xicalango, pero recalcó que no encontró rasgos olmecas (Ruz, 1969: 181,182); de acuerdo con la cronología actual correspondería al Preclásico Medio y Tardío (Ruz, 1969: 273). La segunda época la dividió en dos fases que corresponderían a los complejos cerámicos Tzakol Tardío (hoy fechado como Clásico Temprano) y Tepeu (Clásico Tardío), que encontró en los cinco sitios, y después Tepeu Tardío, halla- 
do en los Guarixés, la ciudad de Campeche y Jaina, también correspondiente al Clásico Tardío.

Una perla significativa de este trabajo es su estudio sobre la problemática ubicación de Xicalango, de la que se han ocupado muchos investigadores sin que todavía haya alguna opinión suficientemente fundada. Primero realizó un análisis de la información contenida en los testimonios históricos acerca de la importancia del sitio como enclave mexica y puerto de intercambio comercial, de acuerdo con las narraciones del siglo xvı, postulando que el asentamiento, después de ser abandonado, desapareció debido a la erosión marina. Propuso que debía encontrarse a medio kilómetro del litoral bajo el agua, en la hacienda del mismo nombre (Ruz, 1969: 52). Sin embargo, la ubicación precisa de este centro comercial nahua-chontal sigue siendo un tema nebuloso. ${ }^{5}$

Su incursión en la multidisciplina marcó todo su trabajo académico; así, antes de excavar en Palenque, Ruz diseñó un extenso proyecto de cinco años de duración, empleando como primera estrategia los estudios de las investigaciones anteriores, de cualquier género, realizados en ese sitio. ${ }^{6}$ El plan de trabajo no sólo incluía la exploración y el estudio arqueológico, sino también la limpieza de los edificios y patios, así como la consolidación y restauración de obras más urgentes. Enumeró una serie de especialistas que necesitaría: antropólogos físicos, dibujantes especializados, ceramistas, etnógrafos, expertos en arquitectura, lingüistas, restauradores e incluso personal de mantenimiento. Sus planes no se limitaban a recoger y clasificar cerámica, sino a conocer los distintos períodos de ocupación y sus cambios, a explorar la evolución de los estilos arquitectónicos de los edificios y al descubrimiento, la limpieza, el dibujo, la consolidación y la restauración de frescos, murales y estucos. Quería descubrir e inventariar las tumbas y estudiar los materiales osteológicos resultantes, innovando los procedimientos desarrollados en otros sitios arqueológicos como Monte Albán y Tlatilco. Fue tan cuidadoso en su proyecto que describía los procedimientos específicos en cuanto al momento y la presentación de informes por él mismo y los arqueólogos participantes. Dado que el acceso al sitio seguía siendo un problema, explicó que iba a gestionar ante el gobierno de Chiapas el compromiso de construir un camino pavimentado desde el pueblo de Palenque a las ruinas.

\footnotetext{
${ }^{5}$ Ralph Roys propuso en 1943 que era el sitio Cerrillos (1943: 101). Lorenzo Ochoa, por su parte, asentó: "Hasta ahora, en contra de lo afirmado por otros investigadores, sólo un sitio parece reunir todas estas características: Santa Rita, situado sobre la margen derecha del rio Sierra que desemboca en la Laguna de Atasta. En apoyo a esta hipótesis citaremos la descripción hecha por fray Tomas de la Torre en 1545, cuando junto con un grupo de frailes dominicos que acompañaba a fray Bartolomé de Las Casas, en su viaje desde España hasta Ciudad Real, Chiapas, tuvo necesidad de quedarse en esa región por un cierto tiempo" (1979: 83).

${ }^{6}$ Cuando empezó el proyecto Palenque, Ruz fue informado por Gordon Ekholm, del Instituto de Estudios Andinos del Museo Metropolitano de Nueva York, que contaría durante cinco años con los fondos Rockefeller. Sin embargo, en realidad fueron sólo tres. Cuando Ruz se enteró que se reducían, tuvo que ajustar su proyecto (Schele, 2012: 132).
} 
Volviendo a la costa campechana, de los años 30 a los 40 la arqueología había cambiado sus objetivos de ser el estudio de la obra suntuaria de los antepasados y de darles una ubicación cronológica a tener una mirada histórica donde debían percibirse los cambios de la relación del hombre con el medio ambiente y sus transformaciones económicas y sociales, principalmente. En este sentido, apuntaba que era momento de comenzar a caracterizar los grandes períodos de tiempo de la historia humana, pero también los de las regiones o culturas específicas (Ruz, 1957).

Puede sorprender que el innovador trabajo de Campeche del doctor Ruz no haya trascendido a los ámbitos científicos nacionales e internacionales con el impacto que era de esperar, y que fuera publicado 24 años después de que se escribió, en 1969. A pesar de ello, se sigue citando, y ahora se puede resaltar su importancia por su originalidad y por ser de avanzada en su tiempo. Wyllys Andrews, en una reseña que hizo dos años después de la publicación, escribió: "Las destrezas de Ruz para excavar son bien conocidas. Sus análisis permanecen vigentes y sus materiales en ningún sentido están anticuados, aunque fuera solamente porque en el interin no se ha hecho ningún trabajo de esta zona" (1971: 424).

Las convicciones sobre la cultura maya que Alberto Ruz defendió a lo largo de toda su trayectoria académica fueron:

1) La universalidad de la cultura maya. Esta idea fue la guía de su afán por colocar dicha cultura dentro de un esquema universal de larga duración de la historia, intento para el que estaba convencido de que el materialismo histórico era la perspectiva más adecuada. Aludió siempre a que la cultura maya era semejante, tanto en su proceso de desarrollo como en sus expresiones materiales, al resto de las culturas antiguas de Europa y Asia, sin que ellas hubieran tenido una aportación directa de sus elementos culturales al pueblo maya.

2) Otro concepto que defendió fue que la cultura maya era autóctona y singular, pero enraizada en el contexto de las culturas mesoamericanas. Quizo demostrar, particularmente, las relaciones permanentes entre el centro de México y el área maya.

3) Postuló la idea de que la investigación debía concentrarse en el desarrollo histórico de la civilización maya, ya que el enfoque que predomina en su visión es el de la antropología histórico-culturalista.

4) Siempre remarcó la permanencia de la cultura y el pueblo mayas hasta nuestros días y que rescatar sus obras materiales era darle vigencia a su pasado glorioso.

5) Otra creencia era la unicidad de la cultura maya, aun cuando sus formas de expresión plásticas tenían muchas vertientes, pues contaba con una amplia variedad de manifestaciones materiales.

6) Propuso que las costumbres funerarias eran parte vital y trascendente de la cultura maya. 
Para defender el primer punto, criticó a George W. Brainerd, a John Eric Sidney Thompson y a Sylvanus Morley; del primero replicó sus interpretaciones acerca de que los mayas tuvieron una cultura excepcional que no encajaba en ningún esquema teórico universal (Ruz, 1981a: 15, 143); del segundo objetó la idea de que la elevación cultural de la civilización maya se debió a fuerzas espirituales (Ruz, 1981a: 77, 144), y al tercero le replicó la idea de que fuera la cultura más brillante del planeta (Ruz, 1948: 6).

Desde que comenzó a escribir, Ruz postulaba la unicidad evolutiva de la historia humana, movida por el desarrollo de las fuerzas productivas, que al entrar en juego provocaban antagonismos entre dos segmentos de la población. Apuntaba: "Tales contradicciones desembocan en la formación de grupos sociales diferenciados y antagónicos y los conflictos que surgen entre ellos actúan como detonadores de cambios históricos trascendentes" (Ruz, 1981a: 79; 1980: 23).

Aplicó las tipologías del materialismo histórico para catalogar a la sociedad maya con los modos de producción, aplicando tanto el de "despótico aldeano", como los de "despótico comunitario" y "asiático", pero al parecer su preferido fue el "modo tributario de producción” (Ruz, 1981a: 79). En su obra sólo hay ciertas alusiones a los argumentos de apoyo de estas interpretaciones, ${ }^{7}$ pero desarrolló las razones por las que eligió hablar de la organización económica y socio-política maya con mayor amplitud en su último libro: El pueblo maya (1981a), donde optó por el "modo de producción asiático" y explicó aquellos rasgos teóricos que encuadraban con la cultura maya, concibiéndola principalmente como una entidad con un sector de la población campesina, con una organización un tanto igualitaria que coexistía con una "unidad superior estatal, que las dirigía y explotaba, apropiándose de los excedentes que aquéllas producían, ya sea imponiendo tributos en especie o utilizando el trabajo de sus miembros a título de pago de servicios" (Ruz, 1981a: 147). Otro tanto hizo en el artículo publicado en 1981, "El Modo de Producción Tributario en el Área Maya", que dejó preparado antes de morir para ser presentado en el Simposio sobre el Modo de Producción Tributario en Mesoamérica, que organizó Alfredo Barrera Rubio en la Escuela de Ciencias Antropológicas de la Universidad de Yucatán, en noviembre de 1979.

Las interpretaciones mencionadas son del año de su muerte, 1979, pero las comenzó a externar desde 1955, cuando después de 20 años de ausencia regresó a Cuba como invitado del Gobierno ${ }^{8}$ para impartir un curso titulado "La Civilización Maya" (1957), en la Universidad de Oriente en Santiago de Cuba, en la Universidad de las Villas en Santa Clara y en otras instituciones culturales. Regresaba como un arqueólogo mexicano triunfador, porque sólo tres años antes había descubierto la tumba de K'inich Janaab' Pakal, pero en Cuba todavía estaba en el poder Fulgencio Batista, el mismo que lo había reprimido y obligado a exiliarse.

\footnotetext{
${ }^{7}$ De hecho, no estudió a fondo los modos de producción como sí lo hicieron en México, en el siglo pasado, académicos como Julio César Olivé, Ángel Palerm o Roger Bartra.

${ }^{8}$ El inicio de la Revolución cubana sería hasta un año después.
} 
Ruz también fue testigo de una violenta represión entre noviembre y diciembre de 1955, la cual aceleró el inicio de la Revolución cubana, y sólo pudo dar una conferencia de las cuatro programadas en la Universidad de Oriente, cerrada en protesta contra Batista.

Hoy en día está vigente su apreciación de la sociedad maya como desplantada de una numerosa base demográfica del pueblo común, organizada en grupos de parentesco, cuya vida interna gozaba de cierta autonomía y que se han llamado familias extensas, segmentos, unidades corporativas (Izquierdo, 2014) y vecindarios, pero al mismo tiempo con una línea de mando vertical. Por lo que Ruz ya delineaba la organización política maya como estructurada por dos formas de gobierno acopladas: las de las comunidades, que él concibe como igualitarias, y la de los centros de poder, encabezados por un régimen aristocrático (Ruz, 1964), con poderes divididos.

Alberto Ruz exaltó de muchas maneras los enlaces de la cultura maya con todas las producciones del género humano (1950: 10-24), y en algunos escritos repitió, siguiendo a Kroeber, que las semejanzas entre culturas eran fenómenos paralelos, surgidos del mismo impulso, que participan de las propiedades de los objetos o de la naturaleza, sólo se parecen hasta cierto punto y difieren del todo en otros sentidos (Ruz, 1963: 26).

Así como defendió los avances y los registros culturales mayas como propios de la naturaleza humana, también se empeñó en exaltar sus particularidades, explicando que era una cultura autóctona, original y, por lo tanto, singular. Rebatió las interpretaciones contrarias a estos postulados en la primera versión de la "La civilización de los antiguos mayas", publicada en Cuba en 1957, resultado de la preparación de sus conferencias de 1955. En ella explica los conceptos difusionistas de Gordon Ekholm, Heine-Geldern, Paul Kirchhoff y Miguel Covarrubias sobre la cultura maya, pero principalmente enfatiza las concepciones de los dos primeros, para criticarlas. Ellos, un año antes del descubrimiento de la tumba real de Palenque, habían publicado un capítulo que llevaba como título "Significant Parallels in the Symbolic Arts of Southern Asia and Middle America", en el libro de Sol Tax: Civilizations of Ancient America: Selected Papers of the XXIXth International Congress of Americas (1951), donde hacían pública información de los trabajos arqueológicos de Palenque, para difundir su interpretación de que varios rasgos de la cultura maya, específicamente de ese sitio, como las columnas serpentinas, el arco trilobulado, los santuarios techados dentro de los templos, el motivo de la cruz y el árbol, el Chac-mool, Quetzalcóatl Kukulcán y otros más, procedían de la India, Indonesia y Camboya. Sospechamos que estos arqueólogos, para apoyar su teoría, usaron los datos de los informes de las excavaciones que Ruz envió entre 1949 y 1951 al Instituto de Estudios Andinos del Museo Metropolitano de Nueva York, pues era Ekholm quien los revisaba. Y quizá también, con un tanto de malicia de su parte, en el año del descubrimiento de la tumba de Pakal (1952), publicaron en español ese mismo artículo con el título "Paralelos significativos en el arte simbólico del sur de Asia y Mesoamérica”, en la revista Tlatoani de la 
Escuela Nacional de Antropología, en donde Ruz también publicó su artículo "Estudio de la cripta del Templo de las Inscripciones (Ruz, 1952).

Un año después, 1953, Ekholm insistió en sus ideas y escribió otro artículo: "A Posible Focus of Asiatic Influence in Late Classic Cultures of Mesoamerica". ${ }^{9}$ Ruz le respondió que en todo el Viejo Mundo se dan rasgos iconográficos semejantes a los mayas y escribió un recuento de ellos, concluyendo que las figuras aludidas eran autóctonas y originales de los mayas:

Las influencias asiáticas tardías que algunos sostienen sin sólidos fundamentos, se refieren a elementos de poca importancia y resultaría incomprensible que nuevos inmigrantes hubiesen traído en una época de gran desarrollo cultural cierta manera de representar la flor de loto, pero sin introducir el arado, la rueda, el carruaje, el torno del alfarero, el arco arquitectónico verdadero, la técnica de la cerámica vidriada, la metalurgia y la religión de Buda (Ruz, 1957: 30; 1963: 27).

Don Alberto señaló también que era comprensible que una tumba suntuosa trajese a la mente las similitudes con las pirámides de Egipto; sin embargo, expresó la dificultad de vincular, seriamente, el origen de la pirámide americana con las del Viejo Mundo. Citó varias razones: una era el problema de la gran separación geográfica entre los dos mundos; otra era la falta de evidencia para otras similitudes en el desarrollo de estas dos civilizaciones, es decir, lo único parecido es la tumba piramidal. La mayor razón que aducía era la de la temporalidad. "Las pirámides de Egipto y el 'Zigurat' en Mesopotamia se remontaba a miles de años, incluso antes que los antiguos pueblos de Mesoamérica comenzaran a construir estas colinas artificiales" (Ruz, 1954: 105).

La oposición de Ruz a las propuestas de Ekholm provocó quizá que, por sus gestiones y las sugerencias de Rosa Covarrubias a Rockefeller, el proyecto Palenque no contara con financiamiento en 1952. Éste se había suspendido desde un año antes por razones poco claras. Los depósitos comenzaron a la siguiente temporada de campo, después del hallazgo de la tumba (Covarrubias, 1954). Aunque Ruz cumplió con todo detalle con sus informes, le detuvieron los fondos cuando más los necesitaba para llegar a la tumba real, pero la excavación siguió adelante con el dinero del Instituto Nacional de Antropología e Historia de México. Los fondos de Rockefeller se repusieron al año siguiente, a petición de la misma Rosa Covarrubias (Covarrubias, 1954).

Por todo lo antes expuesto, don Alberto insistió frecuentemente en que la cultura maya era autóctona y singular, pero enraizada en el contexto de las culturas mesoamericanas; por ello, en la recapitulación de sus conocimientos que hizo al final de su vida en la obra El pueblo maya (1981), también incluye una visión general sobre Mesoamérica en el sentido de que sus rasgos culturales también los comparte la cultura maya. Con relación a su segunda convicción, asentaba

\footnotetext{
${ }^{9}$ Publicado en el número 9 de Memoirs of the Society for American Archaeology.
} 
que la cultura maya, siendo básicamente una por tener una misma matriz, poseyó muchas formas de expresión y, basado en esta idea, se refirió constantemente a la pluralidad de sus obras materiales. Así, cuando hablaba de arte, decía: "Nos estamos refiriendo al arte maya como una unidad, cuando en realidad presenta diferentes estilos, algunos muy cercanos entre sí, otros por el contrario bastante disímiles" (Ruz, 1957: 104), atribuyendo estas diferencias al medio ambiente (Ruz, 1957: 105; 1963: 82, 83). Más tarde ya no suscribe la ecología cultural y, en su lugar, afirma que el arte es un producto social derivado de la realidad política, y que "La división política del territorio maya en estados autónomos explica la diferenciación de estilos" (Ruz, 1979b: 207), de ahí se explica que parte de su curso se desarrollara conforme a los estilos artísticos en que se había dividido el área maya, asumiendo estos espacios como entidades políticas.

A Ruz le animaba el debate académico y la mayoría de las veces comenzaba la exposición de sus resultados ubicando al lector en las interpretaciones con las que no estaba de acuerdo, siempre con argumentos convincentes. Su primera oposición abierta fue a las concepciones de Sylvanus Morley, que empezó a criticar tan temprano como sus excavaciones en Campeche le fueron dando datos sobre la ocupación temprana del área. La primera vez que detractó las ideas de Morley fue en un artículo que salió a la luz justamente antes de su examen profesional de 1945: "Arqueología maya: trayectoria y meta”, en el volumen XXII de Cuadernos Americanos. Quizás este artículo fue la respuesta de Ruz a la publicación de las teorías de Morley, por primera vez en español, en la Enciclopedia Yucatanense, vol. II: Época Maya (1945); después, en varios de sus trabajos repitió sus objeciones, pero la más amplia y detallada de las versiones la publicó en el volumen VI de Acta Americana, en 1948, incorporada a una reseña que redactó con base en la primera versión en español de Ancient Maya, que publicó el Fondo de Cultura Económica en 1947.

Morley postuló la existencia de dos períodos sucesivos en la cultura maya, cuyos florecimientos tuvieron lugar en territorios distintos: el Antiguo Imperio y el Nuevo Imperio. El primero habría visto su cumbre cultural en las tierras bajas tropicales de Chiapas, Guatemala, Honduras y Belice, y colapsado culturalmente hacia el siglo Ix, a causa de lo cual sus habitantes despoblaron el territorio y ocuparon Yucatán, dando origen a un nuevo renacimiento maya-tolteca al que denominó Nuevo Imperio. Los argumentos de Ruz no sólo fueron los hallazgos en Campeche del Preclásico, al que, por aquel tiempo se llamaba "Arcaico o Premaya", sino de todas las recientes excavaciones en el área maya y en Mesoamérica en general. Concluyó:

Se ha comprobado en los últimos años que durante los primeros tres siglos de nuestra era y quizá en un período anterior, existió tanto en la zona atribuida al Viejo Imperio como en la península yucateca, una cultura premaya, asociada en antiguiedad y por sus características al "Arcaico" del Centro de México, a la cultura llamada de La Venta y olmeca de Veracruz y Tabasco, al período más antiguo de Monte Albán 
en la región zapoteca, y Monte Negro en la Mixteca, siendo las fases más remotas de Uaxactún, San José y Miraflores, las manifestaciones mejor conocidas de aquel primer horizonte cultural de Mesoamérica, en lo que después se vuelve asiento de los mayas (Ruz, 1945, en Izquierdo, 1987: 67; Ruz, 1948).

Desde la primera edición en español de la Civilización Maya de Morley, su esquema sobre el devenir maya se consideraba anacrónico y desautorizado entre los mesoamericanistas profesionales, según explicaba Ruz, porque había sido creado por Morley en 1915 (Ruz, 1981: 13) cuando publicó, con el Smithsonian Institute, An Introduction to the study of Maya Hieroglyphs, donde si bien no usa la palabra "imperio", sí narra la existencia de dos periodos en la historia maya: uno de gran florecimiento en las tierras bajas del sur, y otro, posterior, en la península de Yucatán (Morley, 1915, 1945, 1947).

Esta visión seguía vigente en los textos escolares de historia de México, debido a que la expuso en su libro general sobre los mayas desde $1946,{ }^{10}$ obra que supo de múltiples ediciones en inglés y en español. Enseguida que Ruz escribió estas objeciones, llamaba la atención acerca de que dichas interpretaciones solamente seguían en vigor "en los textos escolares de historia patria, los que por muchos motivos claman por sustitutos más apegados a la verdad" (Ruz, 1945, en Izquierdo, 1987: 67). Su llamado, repetido múltiples veces por los prehispanistas, sólo fue oído hasta después de 60 años.

Alberto Ruz y Evon Vogt fueron amigos; así, cuando el primero funda Estudios de Cultura Maya (1961), bajo el auspicio del Instituto de Investigaciones Históricas de la Universidad Nacional Autónoma de México, de inmediato el segundo manda su artículo "Some Aspects of Zinacantan Settlement Patterns and Ceremonial organization", en donde, con base en sus trabajos de etnología entre los zinacantecos de Los Altos de Chiapas, y trasladando la información sobre el sistema rotatorio de cargos entre los tzotziles y su alternancia entre actividades campesinas y sacerdotales a la naturaleza política de la sociedad maya, propone que en la época Clásica los mayas vivían en una sociedad igualitaria (Vogt, 1961: 143).

La preparación de este artículo para su publicación movió a Ruz a expresar convicciones contrarias y escribió el texto llamado "Aristocracia o democracia entre los mayas" (Ruz, 1964b y 1984). Partiendo del principal postulado que siempre defendió, relativo a la existencia en la sociedad maya de "clases sociales" tajantemente diferenciadas, expuso argumentos arqueológicos concernientes a una compleja jerarquía de casas habitación y textos epigráficos relativos a las inscripciones que refieren la vida de poderosos gobernantes. Basó tales argumen-

${ }^{10}$ Sylvanus Griswold Morley, The Ancient Maya. Stanford: Stanford University Press, 1946. Adrián Recinos la tradujo y se publicó en México apenas un año después (Los antiguos mayas. México: Fondo de Cultura Económica, 1947). La interpretación de Morley se difundió ampliamente en Yucatán, con la versión corta en Historia general de los antiguos mayas, vol. 2 de la Enciclopedia Yucatanense. Yucatán: Gobierno de Yucatán, 1945, texto al que Ruz debió tener acceso antes, quizá, de la edición en inglés impresa en Estados Unidos. 
tos en la imposibilidad de que los datos etnológicos sobre el sistema rotativo de cargos en Zinacantán fueran el reflejo de lo que estilaban los mayas en la época prehispánica (Ruz, 1964b y 1984).

No obstante sus discrepancias, siguieron siendo amigos y trabajaron juntos en editar un libro que se volvió clásico para los mayistas: Desarrollo cultural de los mayas (1964c), uno de los textos en los que Ruz continúa con su convicción de que la investigación en torno a los mayas debía concentrarse en su desarrollo histórico. Participaron los investigadores más significativos del momento: Tatiana Proskouriakoff, Norman McQuown, Terrence S. Kaufman y Alfonso Villa Rojas, entre otros. Esta obra fue el resultado del congreso que se llevó a cabo en septiembre de 1962 en Austria, organizado por la Wenner-Gren Foundation for Antropological Research. Ese encuentro académico fue muy significativo para Ruz porque se expuso la idea de integrar un equipo multinacional y multidisciplinario de investigadores que estudiaran las lenguas mayas, los diccionarios coloniales y todas las inscripciones conocidas, idea que hizo suya y ofreció que la coordinara el Seminario de Cultura Maya de la Universidad Nacional Autónoma de México, con la colaboración del Instituto de Historia y del Centro de Cálculo Electrónico de la misma institución. Así fundó la Comisión para el Descifre de la Escritura Maya en 1964 (Ruz, 1964d: 375) o Comisión Mexicana para el Estudio de la Escritura Maya, ${ }^{11}$ apoyada con financiamientos de la fundación Wenner-Gren, de Nelson Rockefeller (Boyer, 1965) y del Instituto Nacional de Antropología e Historia. Lamentablemente, por falta de presupuesto, en 1968 se convirtió en Seminario de Estudios de la Escritura Maya, y desapareció en 1970. Éste fue el primer grupo de trabajo, y el único hasta ahora en México, cuya sola finalidad era avanzar en los métodos y logros para el desciframiento de la escritura maya (Ayala, com. pers., 2013). Algunos de los participantes permanentes fueron María Cristina Álvarez, Maricela Ayala Falcón, Juan Ramón Bastarrachea, Martha A. Frías, Leonardo Manrique Castañeda, Juan José Rendón y Daniel Cazés, este último fungiendo como director.

Su trabajo tuvo resonancia nacional e internacional: organizaron el Primer Seminario Internacional para el Estudio de la Escritura Maya (1966), con el apoyo y la ayuda de Alfredo Barrera Vázquez. De este evento contamos con las crónicas en español de Leonardo Manrique Castañeda (1968) y la de Nicholas Hopkins, en inglés, publicada en Latin American Research (1967). Estuvieron presentes Mauri-

\footnotetext{
${ }^{11}$ Varían los nombres de esta institución en los mismos textos de Ruz y en los de los otros participantes. En el primer texto en que aparece es bajo el nombre de Comisión para el Descifre de la Escritura Maya (Ruz, 1966: 182), mientras que en el discurso inaugural del Primer Seminario que organizó le denominó Comisión Mexicana para el Estudio de los Glifos Mayas. Después se llamó Comisión para el Estudio de la Escritura Maya, y a partir de 1968 se convirtió en Seminario de Estudios de la Escritura Maya (Ruz, 1968b: 24), entidad que desde un principio estuvo adscrita a la Coordinación de Humanidades de la UNAM. Las explicaciones a estos cambios fueron descritas por Ruz en el prólogo a la edición de Estudios de Cultura Maya, VIII. Con fecha 15 de junio de 1970 —apuntó allí- se integró el Centro de Estudios Mayas, "con el objeto de coordinar en un solo organismo los trabajos que han venido realizando del Seminario de Cultura Maya de la Facultad de Filosofía y Letras y del Seminario de Estudios de la Escritura Maya de la Coordinación de Humanidades" (Ruz, 1968b: 23-32).
} 
cio Swadesh, Tomas S. Barthel. David H. Kelley, Floyd Lounsbury, Michael Coe, George Stuart y Judy Kathryn Josserand, entre los académicos más distinguidos del momento, que procedían de los Estados Unidos y de Alemania. Pero también la representación mexicana fue muy importante, con un interesante equilibrio entre unos y otros. La mayoría de las ponencias fueron publicadas en Estudios de Cultura Maya, VII, en el turbulento año de 1968, con la colaboración de los primeros epigrafistas mexicanos como Maricela Ayala.

Otra disputa académica surgió en 1974 durante la Segunda Mesa Redonda de Palenque, dedicada ese año al análisis del sepulcro de K'inich Janaab' Pakal, el más importante soberano de Palenque. Esta discusión empezó cuando los epigrafistas expusieron sus nuevas lecturas y se confrontaron con las interpretaciones de otros investigadores.

La tumba descubierta por Ruz ostentaba en la parte superior una losa tallada, que tenía esculpidas en sus cantos varias fechas de ruedas calendáricas. No había cuentas largas que pudieran datar precisamente la historia personal del inhumado. Ruz había comenzado a llamarle al hombre de la tumba "Uaxac Ahau" u "8 Ahau", fecha del almanaque sagrado (1975: 218), sabiendo que en varias culturas mesoamericanas los personajes llevaban nombres calendáricos como el mixteco 8 Venado Garra de Tigre.

En el momento de descubrir la tumba, la osamenta del monarca fue estudiada por los antropólogos físicos Eusebio Dávalos Hurtado y Arturo Romano Pacheco, quienes escribieron tres cuartillas y media de sus conclusiones, las cuales fueron incorporadas en el informe de Ruz de la temporada 1952, publicado en los Anales del Instituto Nacional de Antropología (1954). Don Alberto precisó que era un trabajo preliminar (Ruz, 1954), ya que la mandíbula y el cráneo se trajeron a México para realizarles más análisis. Concluyeron que el esqueleto pertenecía a un hombre adulto, alto de estatura y robusto de constitución, y reportaron que su edad probable era de entre 40 y 50 años, con base en el poco desgaste de la dentadura, según lo afirmó Arturo Romano más tarde, en el texto que formó parte del libro de Ruz El Templo de las Inscripciones, Palenque (1973b: 253-254). En ese tiempo, los análisis físico-químicos para determinar la edad de los huesos no existían, así que los resultados estuvieron de acuerdo al desarrollo de la antropología de esa época.

Cuando Ruz presentó sus resultados en la Segunda Mesa Redonda de Palenque (1974), comunicó sus propias lecturas del canto de la lápida que cubría el sarcófago, incluyendo sus propuestas del nacimiento y de la muerte del personaje de la tumba. Sus interpretaciones manifestaron que la edad del personaje enterrado en la cripta sería de 39 años de edad. Su presentación no fue bien recibida, porque contradecía las lecturas de Peter Mathews y Linda Schele, quienes en la Mesa Redonda del año anterior habían sostenido que vivió 80 años, pero la señora Green publicó la ponencia de Ruz en las memorias de la Mesa, The Art, Iconography and Dynastic History of Palenque (1976).

Hace casi una década, Vera Tiesler y Andrea Cucina coordinaron el libro Janaab' Pakal de Palenque. Vida y muerte de un gobernante maya, donde, después de realizar 
nuevos análisis de los huesos de K'inich Janaab' Pakal, con el concurso de un equipo internacional de investigadores de histología, que tomó en consideración los cambios morfoanatómicos, se concluyó que había muerto a una edad avanzada, que había sufrido osteoporosis y artritis, y que su edad era superior a los 55 años, datos compatibles con los estudios de los epigrafistas (Tiesler y Cucina, 2006: 265-266 y 26), y no lejanos a las primeras conclusiones de Romano.

Otro tema de debate académico en el que Ruz participó con George Kubler fue el de las influencias del Altiplano Central en el área maya. Inició Kubler con un artículo en el número inaugural de Estudios de Cultura Maya titulado "Chichén Itzá y Tula", donde propuso la hipótesis de que "no hay nada en Tula que corresponda a los primeros períodos del arte tolteca de Chichén Itzá. Esto sugiere que Tula fue más bien una avanzada colonial de Chichén Itzá en vez de lo contrario" (Kubler, 1961: 64).

La respuesta de Ruz se imprimió en Estudios de Cultura Maya II con el título "Chichén Itzá y Tula, comentarios a un ensayo" (Ruz, 1962). En su interpretación consideró los rasgos formales enumerados por Kubler como originarios del área maya, pero presentes en otras culturas (Ruz, 1962; Izquierdo, 1987: 39), principalmente del Altiplano de México. Desglosa cada rasgo iconográfico al que alude Kubler y discute su matriz ampliamente, para concluir:

el período tolteca de Chichén muestra la continuación de la cultura Puuc, alterada notablemente por la cultura tolteca y por elementos que acompañan la difusión de ésta. La presencia de motivos atribuibles a otros núcleos como Petén, Oaxaca, Teotihuacán, se explica por los antecedentes tanto de la cultura Puuc como de la tolteca, ya que cada una en su área se integró por tradiciones más antiguas (Ruz, 1962: 218).

En ese mismo volumen de Estudios de Cultura Maya, Kubler le replica a don Alberto, destacando más bien las coincidencias que se encuentran en ambos análisis de rasgos iconográficos (Kubler, 1962), pero sin escalar en su argumentación.

El asunto de la presencia de una determinada colección de elementos iconográficos distintos a lo maya en Chichén Itzá es consenso general de los investigadores, pero se considera que sólo una parte de ellos fue de cuño tolteca. Así, algunos, siguiendo un tanto la línea de Kubler, presentan evidencias que sustentan la interpretación de que la arquitectura y, en general, el arte de Chichén Itzá son una combinación sincrética de rasgos mayas tradicionales (Kowaleski, 2007: 41).

Desde estos dos primeros artículos de Ruz en Estudios de Cultura Maya, el tema de las presencias del Altiplano de México en el área maya le apasionó y produjo varios textos con esta temática. Es significativo "Influencias mexicanas sobre los mayas" (1964c) para el simposio en Austria de la Wenner-Gren y después para el libro Desarrollo Cultural de los Mayas, donde detalla su estructura desde una perspectiva histórica, esto es, identificando las presencias "mexicanas" a lo largo de la trayectoria histórica maya y describiendo espacialmente lo hallado en las áreas septentrional, central y meridional. En este texto explica que el término 
mexicano alude al espacio geográfico del Valle de México (Ruz, 1964c: 204). En sus conclusiones, como en muchos de sus otros trabajos, presenta interpretaciones fundadas, pero deja entrever que su certeza siempre es parcial. Asimismo, señala presencias no sólo de raigambre centro-mexicana, sino de culturas de la costa atlántica o de la vertiente pacífica de Oaxaca y Guerrero (Ruz, 1964c: 225).

Aunque Ruz discute poco las fechas de la plenitud tolteca de Chichén Itzá en su último libro: Chichén Itzá en la historia y en el arte (1979b), elabora una cronología, fundamentalmente con datos de las fuentes escritas, pero también con los avances que hasta esa fecha se tenían de la arqueología de la zona. A su parecer, esta ciudad sufriría varias oleadas migratorias en el siglo x y florecería como sitio maya-tolteca entre los siglos XI y xII d.C. para ser abandonada en el katún 8 Ajaw, finales del siglo xII y principios del xIII (Ruz, 1979b: 61-67). Una interpretación que ha sido seriamente objetada con las actuales reconstrucciones multidisciplinarias de la historia de Chichén, ya que, por ejemplo, los investigadores han expresado que el fin de Chichén Itzá ocurrió a finales del siglo x d.C.

Otro aporte de Ruz que es necesario destacar fue la intensidad de sus trabajos de campo. En Palenque realizó 10 temporadas, de 1949 a 1958, cuyos resultados han sido frecuentemente comentados y forman parte de la historia de los estudios arqueológicos de esa capital maya, aunque hayan sido discutidos o superados, pero lo que ha permanecido un tanto en la sombra es que en su puesto de jefe de la Zona del Sureste de la Dirección de Monumentos Prehispánicos de Instituto Nacional de Antropología (1947-1958), además de realizar sus labores administrativas, excavó en Uxmal, Kabah, Sayil, Chichén Itzá, Tulum y otros sitios de Quintana Roo. Ya que la estación de lluvias en Palenque es muy fuerte, haciendo imposible excavar, realizaba otros trabajos de campo en la península de Yucatán, mientras vivía en Mérida, con su familia, e interactuaba académica y socialmente con los estadounidenses que estudiaban el área. De todas sus intervenciones y excavaciones presentaba informes al Instituto Nacional de Antropología, ofreciendo siempre novedades (figura 3).

Merece una mención especial que en 1947 exploró Uxmal, eligiendo la terraza al poniente de El Gobernador y su trabajo se vio coronado con el hallazgo de un edificio antiguo, probablemente del siglo vill d.C. (Izquierdo, 1987: 24). El edificio resultó singular porque su estilo arquitectónico no era Puuc, la forma de construir típica de Uxmal, pues su fachada multiforme representaba el rostro de una deidad, como los edificios de la región Chenes.

Otro aporte de Ruz al pasado prehispánico no valorado en toda su dimensión fue su labor de consolidación y restauración, que en ese entonces no eran una disciplina, aunque debían basarse en la normativa internacional como la Carta de Atenas de 1931, protocolo que pudo haber sido su guía. Comenzó reflexionando sobre el sentido de esta labor en un artículo de 1944 que tituló "El sentido humano de la arqueología" (Ruz, 1944). En él, además de desarrollar su visión humanista del conocimiento arqueológico, asentaba que el arqueólogo no sólo debe conocer y difundir la obra cultural de un pueblo; también está 
obligado a reconstruir y salvar de la destrucción el patrimonio que otros pueblos legaron a la humanidad.

La reconstrucción de una ciudad que vuelve a surgir a la luz liberada de su sudario de escombros y restañadas sus heridas, no constituye una devolución sólo en sentido material, plástico. Al rescatar del olvido y de la muerte los tesoros de una civilización desaparecida, restituimos a la memoria de sus creadores y portadores los méritos que lograron adquirir y que las generaciones posteriores ignoraron o vilipendiaron, pero cuando una raza como ésta sigue aún capaz de vivir, luchar, pensar, creer al poner ante sus ojos el testimonio revivido de la grandeza de sus antepasados, le restituimos lo que por derecho le pertenece, el propio patrimonio (Ruz, 1944, en Izquierdo, 1987: 56).

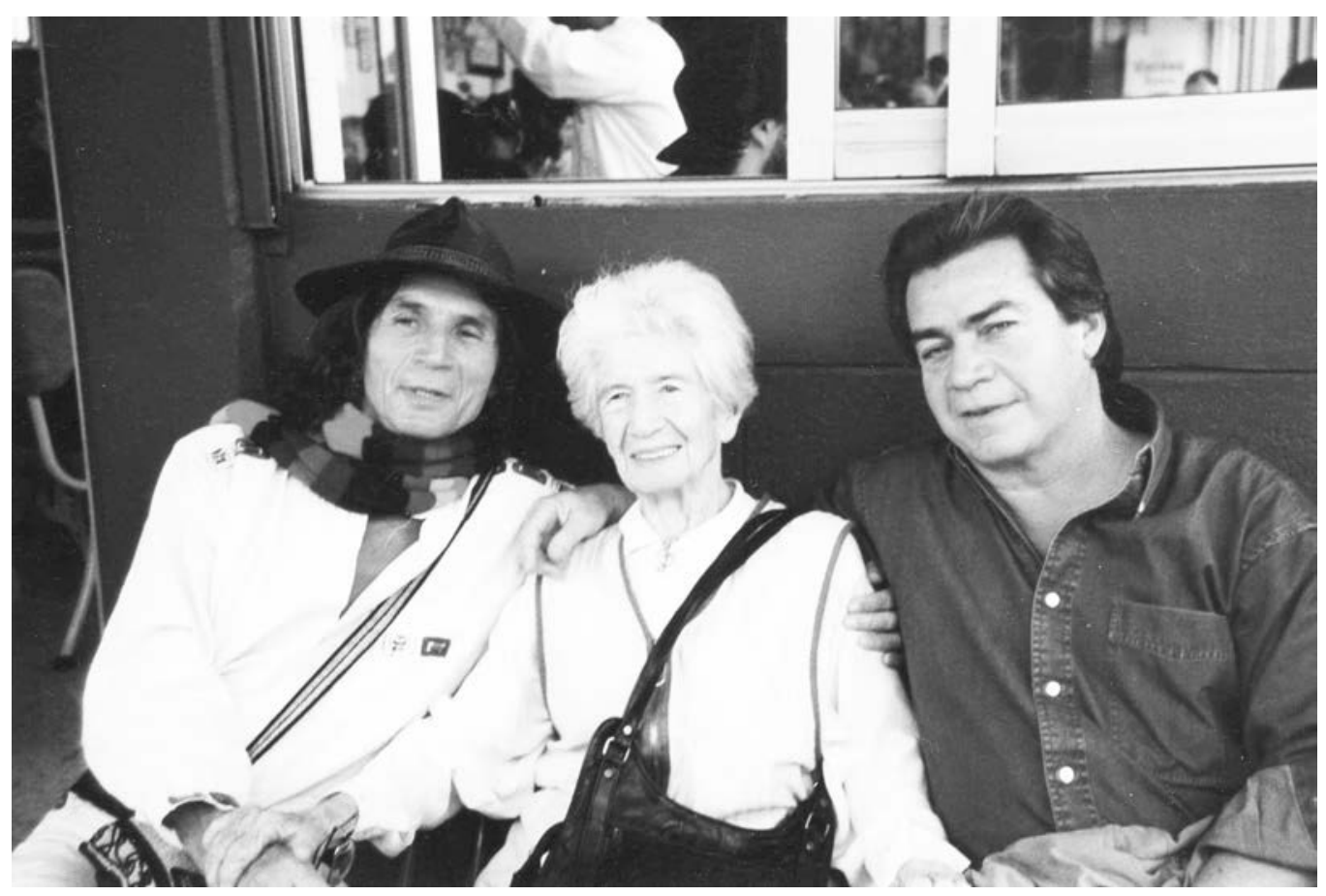

Figura 3. Blanca Buenfil con sus hijos Alberto y Jorge Ruz, $<$ https://www.facebook.com/photo.php?fbid=10152992925352893\&set $=$ t.525147892\&type $=3 \&$ theater $>$.

Coherente con este principio, dedicó varios meses de los años 1950, 1951, 1952 y 1956 a la consolidación y restauración del Palacio del Gobernador, el Cuadrángulo de las Monjas, el templo poniente del Adivino, El Palomar y el templo 
llamado El Cementerio de Uxmal, todo ello como jefe de la Oficina de Monumentos Prehispánicos de Yucatán y de la Zona Arqueológica del Sureste, encargo que recibió del INAH en 1947.

Desde que Ruz fue nombrado jefe de las exploraciones en Palenque, en su plan de trabajo, entregado sólo un mes después, plantea, además de efectuar los procesos arqueológicos sustantivos para su investigación, realizar el desmonte y limpieza de edificios y patios y, lo más urgente, la consolidación y la restauración (Schele, 2013: 25).

Sus trabajos de restauración en Palenque también se originaron en los intereses del presidente Miguel Alemán, para quien abrir puntos de interés para el turismo era una alta prioridad, y por los de Nelson Rockefeller, al enterarse del estado de las ruinas; de ellos dos dependía el financiamiento (Schele, 2012: 2425). Sus intervenciones no se limitaron a la arquitectura, sino también a los estucos y a la pintura mural, y hay quien afirma que fue más del $60 \%$ de su trabajo total en Palenque lo que redundó en que se vio forzado a modificar las metas multidisciplinarias esenciales de su trabajo de investigación arqueológica.

Cuando realiza sus 10 temporadas de campo en Palenque (1949-1958), efectúa restauración en el Palacio, así como en la torre, el Templo de las Inscripciones (figura 4), el Templo XIII y el acueducto, a la altura del Palacio. Asimismo trabaja en el Grupo III o los Murciélagos y el Grupo IV. Para ello siguió los cánones de su tiempo, es decir, de Manuel Gamio y Sylvanus Morley, pero principalmente los de Alfonso Caso.

Aunque hay que analizar su obra de reconstrucción a la luz de su tiempo, la única reedificación realizada que ha resultado polémica ha sido la de la torre del Palacio. Stephen Black (1990: 131-136) y Daniel Schávelzon (1990: 156) creen que realizó un techo con indicios no certeros. Asimismo expresan que fue "hipotética" y que el techo de mampostería que puso Ruz en la reconstrucción no debió ser tal, ya que originalmente fue de madera y ramas, o también pudo ser plano, hecho con vigas de madera (Schávelzon, id.). Sin embargo, en el informe de la temporada de excavación de 1951, publicado en Anales en 1952, claramente asienta que exploró la torre y que limpió y sacó el escombro que pertenecía al techo del tercer piso. La palabra "escombro" se refiere a restos de mampostería, es decir, a residuos de obra arquitectónica de piedra, por lo tanto el techo pudo haber sido de piedra. Apoyan esta interpretación las copias de los dibujos que se encuentran en el American Museum of Natural History (Ruz, 1949a) hechos por el equipo de Ruz, y los dibujos de la torre claramente muestran que su techo y cornisas habían caído al interior, quedando sobre el piso (Ruz, 1952: 56-57).

Otra aportación de Ruz que tampoco ha sido valorada en toda su dimensión es su defensa del patrimonio arqueológico nacional. En ese rubro, no sólo escribió para denunciar el saqueo, sino que logró detener a los depredadores y hasta entró en pugna con autoridades estatales, que culminaron en un gran encono hacia su persona por parte del gobernador de Yucatán, Agustín Franco Aguilar. 


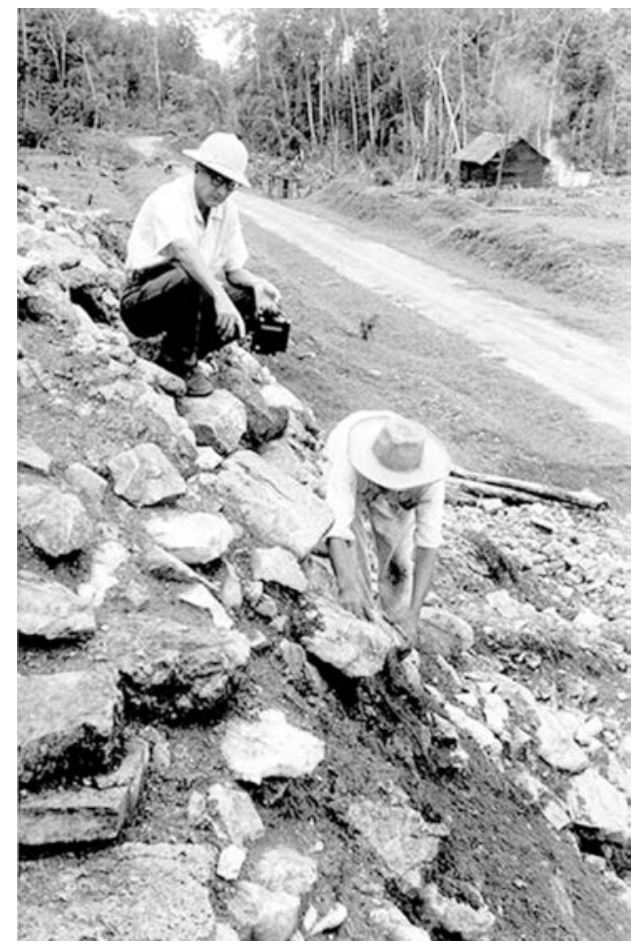

FIGURA 4. Ruz dirigiendo la reconstrucción de la escalera del Templo de Las Inscripciones de Palenque. Archivo Miguel Covarrubias, Universidad de las Américas, Dirección General de Bibliotecas, Arquitectura Maya I (Dibujos, Fotografías y Recortes). Fotografía de Rosa Covarrubias.

Desde que se trasladó de Campeche a Mérida a tomar su puesto de jefe de la Zona del Sureste de la Dirección de Monumentos Prehispánicos del Instituto Nacional de Antropología e Historia (1949-1958), llegó con el objetivo de hacer valer la Ley sobre protección y conservación de monumentos arqueológicos e históricos, poblaciones típicas y lugares de belleza natural (1934), que en sus primeros siete artículos, además de declarar que estos bienes eran dominio de la nación, prescribía su protección por parte de las autoridades federales; incluso los inmuebles particulares con vestigios arqueológicos debían ser vigilados por las autoridades. Con base en esta normatividad, cuando llegó don Alberto a ocupar la citada jefatura, comenzó a recorrer Mérida y sus alrededores, y, haciendo labores de detective, se dio cuenta de que había expendios de piedra caliza, cuyo origen eran construcciones prehispánicas, para la construcción en terrenos particulares, donde además se trituraba la piedra, o se molía para polvo. Con la ley en la mano, detuvo o trató de detener la destrucción de arquitectura prehispánica en Hopelchén, Chichén Itzá, Acanceh y Umán; para ello hablaba con los dueños de esas "fábricas", y si no obtenía nada, no se detenía en enviar a 
algunos a la cárcel. No es de extrañar que entrara en conflicto con los ingenieros que abrían caminos en ese entonces y, como consecuencia, con las autoridades locales. Uno de los casos más relevantes fue la construcción del mercado municipal de Mérida donde se destruyeron los últimos restos de la pirámide que fray Diego de Landa describió y dibujó en su crónica, según interpretación del arqueólogo (Ruz, 1968c). También denunciaba el saqueo de edificios y tumbas para sacar piezas antiguas, principalmente cerámica y figurillas, o llevarse dinteles y estelas.

Ante la insistencia de acusar a particulares y autoridades de violar la Ley sobre protección y conservación de monumentos, en los círculos sociales de Mérida se decía que Ruz era un hombre que tomaba demasiado en serio el problema de la destrucción de las ruinas, y que se tenía que cuidar "porque podría tener algún accidente en el monte" (Ruz, 1968c).

El acto de defensa más álgido al que Ruz se enfrentó tuvo lugar en 1958. En ese entonces le fue entregado un libreto por la compañía Editions Gilbert para obtener el permiso de filmar en las ruinas de Chichén Itzá una serie con un personaje que ya era popular en ese tiempo: "El Fantasma de la selva". ${ }^{12}$ Don Alberto encontró el guión ofensivo pues mostraba a los mayas como personas ridículas (Ruz Buenfil, com. pers., 2014; Castro, 1958: 8), cuando sus afanes eran devolver a los mayas contemporáneos conciencia de su pasado creativo y glorioso. Así, previa consulta con el director del INAH, negó el permiso.

Ya que las autoridades federales habían negado la aprobación, el productor se acercó a la familia Barbachano, propietaria de las tierras donde está enclavado Chichén Itzá. Como para ellos era un jugoso negocio, apelaron al gobernador de Yucatán, Agustín Franco Aguilar (1958-1964), quien dio la autorización, pasando sobre la ley de 1934.

En ese entonces, mayo de 1958, se había fundado el Instituto Yucateco de Antropología e Historia en colaboración con el Instituto Nacional de Antropología e Historia, en el que participarían los gobiernos federal y estatal. Como director quedó el antropólogo Fernando Cámara Barbachano, primo de Fernando Barbachano, el prestador de servicios turísticos más importante de la zona (Castro, 1958: 4).

Tanto por ello, como porque era rechazado por las autoridades locales, ya que veían en él una amenaza contra sus objetivos desarrollistas, Ruz renunció al cargo de jefe de la zona arqueológica del Sureste, pero debió seguir en el puesto hasta hacer oficial su relevo, lo que sucedió el 15 de octubre de 1958 (Salazar, 1961).

Al empezarse a filmar la serie, Ruz usó todos sus recursos para evitar que siguieran adelante, pero lo único que consiguió fue enardecer al gobernador, quien comenzó a tratar de fabricarle algún delito para encerrarlo y acallar sus

\footnotetext{
12 Agradecemos cumplidamente las aportaciones de Alberto Ruz Buenfil para obtener una narración más fiel de los hechos. El documento que nos hizo llegar cuando estábamos terminando este artículo nos hizo modificar varias partes de nuestra primera versión, al aclararnos detalles de los sucesos. El texto es de una enorme significación pues fue escrito por Rosa Castro, una de las primeras mujeres periodistas que trabajaron en México (Pitman, 2007: 132-133).
} 
reclamos. La narración de la periodista Rosa Castro, de este evento, parece ser la más verídica de las que hemos escuchado, porque su artículo fue leído por Ruz y hasta corregida la redacción. Siguiendo su relato, ocurrió que el automóvil de don Alberto estaba en un taller y el mecánico lo sacó y atropelló a un ciclista. El domingo 12 de octubre de 1958 le regresó el automóvil ensangrentado en la casa de Andrews. Por la noche Ruz se enteró de los acontecimientos y decidió aclarar el asunto con la policía. Al día siguiente fue encarcelado e incomunicado mientras la filmación se llevaba a cabo en Chichén Itzá, pese a que, por órdenes de Ruz y de Ponciano Salazar, quien ya era el titular de la jefatura del INAH en Yucatán, se impidió al equipo la entrada. Salazar se comunicó con Eusebio Dávalos Hurtado, director del Instituto Nacional de Antropología e Historia, quien apoyaba la decisión federal, confirmando la negativa de permiso. Sin embargo, Fernando Barbachano y Gilbert se presentaron en la delegación del INAH y dijeron que se filmaría "a como diera lugar" y que rompían toda relación con la institución federal. Las palabras de Castro de este evento son muy vívidas: "Palabras evangélicas las del señor Barbachano: en efecto, al día siguiente, la Editions Gilbert, con la protección de la policía del estado, tomo posesión de Chichén Itzá y alegremente soltó a su fantasma de la selva” (Castro, 1958: 6).

No obstante, según consta en su curriculum, Ruz continuó como investigador del Instituto Nacional de Antropología e Historia hasta 1960, aunque desde enero de 1959 ingresó al Instituto de Historia de la Universidad Nacional Autónoma de México con un contrato para formar el Archivo Bibliográfico de la Cultura Maya (Ruz, 1979a), firmado por el notable científico Nabor Carrillo. Ahí fundó el Seminario de Cultura Maya con el mismo perfil del Seminario de Cultura Náhuatl que dirigía Ángel María Garibay. Para 1960 el nuevo Centro de investigación se trasladó a la Facultad de Filosofía y Letras de la Universidad Nacional Autónoma de México. Por entonces su contrato se refería ya a labores de docencia y a la dirección del seminario (Ruz, 1979a).

Otra aportación de Ruz, tampoco destacada, es el haber realizado el primer resumen de todo lo que se conocía, hasta su tiempo, sobre la cultura maya para su difusión, realizado en español y por un mexicano. Otra veta de los aportes de Ruz a la difusión científica de la cultura Maya.

Laborando aún en el Instituto Nacional de Antropología e Historia, en 1957, se publicó su obra La civilización de los antiguos mayas en la Universidad de Oriente en Cuba, texto que el INAH imprime en México hasta 1963: después se publicó en francés y en inglés (1964a, 1970a), con prólogos de Guy Stresser-Pean y Eric Thompson respectivamente. La obra supo en total de siete ediciones hasta 1981 y luego otras cuatro ediciones en el Fondo de Cultura Económica, al parecer la última en 2011. Existe además una versión para tableta Kindle.

La relevancia de esta obra es que, cuando salió el libro por primera vez, era un resumen actualizado de la trayectoria histórica y de las creaciones culturales en español realizada por un mexicano. En su momento sólo estaban las obras de Sylvanus Morley: La historia antigua de Yucatán: El nuevo imperio (1942), traducción 
de una obra en inglés de 1936, y la Historia general de los antiguos mayas, traducida y publicada en español en 1945, y en inglés en 1946.

Uno de los diversos aportes a resaltar de este libro de Ruz es que objeta conceptos de los estadounidenses sobre los mayas que en su época se habían difundido mucho y eran muy aceptados por un amplio grupo de mayistas.

Otro tema que ocupó las labores de investigación de Ruz fue el de las costumbres funerarias de los mayas, con lo que obtuvo el grado de doctor en Antropología en la Universidad Nacional Autónoma de México, en noviembre de 1965. Fascinado por las prácticas mexicanas ante la muerte, tanto de indiferencia como de familiaridad, que ciertos filósofos de los años cincuenta consideraron como falta de apego a una vida difícil, llena de obstáculos, en la que la muerte no era una desgracia sino una liberación (Ruz, 1968, 1968a:11). En consecuencia, la hipótesis inicial de su investigación fue demostrar que estos sentimientos tienen su origen en la época prehispánica: "Las razones profundas que pueden explicar el tratamiento que el mexicano da a la muerte, deben por lo tanto buscarse en su vivencia autóctona" (Ruz, 1968a: 13).

En esta investigación están vertidos todos los principios que don Alberto siempre sostuvo en su obra escrita y en su labor docente, descritos al inicio de este trabajo, pero particularmente en Costumbres funerarias de los antiguos mayas (1968); para demostrar la universalidad de la cultura maya como sus particularidades se basó en el comparativismo cultural. Así, en el texto desfilan el examen y parangón de las prácticas mortuorias mayas con las del resto de Mesoamérica (subrayando la raigambre mesoamericana de los tipos de entierros y sus peculiaridades en los usos mayas), de América en sus partes norte, central y sur, y del Viejo Mundo, principalmente de Europa, el Cercano Oriente, la India y de lo que hoy es Tailandia y Camboya. Así demuestra la universalidad de la cultura maya y destaca sus diferencias y peculiaridades en estas costumbres.

Esta obra también manifiesta su inquietud por ubicar la temporalidad de las prácticas funerarias, para que no se escaparan en su visión general de la cultura maya, los cambios y los procesos; así, tiene un capítulo en el que reúne todos sus datos para, en forma muy ordenada, organizarlos con el título "Distribución geográfica y situación cronológica de elementos funerarios en el área maya" (Ruz, 1968a: 149-167).

El interés de Ruz por no desvincular a los mayas actuales de su pasado también está presente en este libro, de allí que inicie desarrollando las características del culto funerario entre los mayas actuales, pero distribuyéndolas geográficamente por áreas. No unifica a todos los pueblos de lenguas mayanses porque continúa en la línea de destacar sus especificidades en el ámbito de su unidad cultural. Tampoco separa estas tradiciones del todo sociales y así dedica dos capítulos a las implicaciones tecnológico-económicas y sociológico-políticas, así como las implicaciones ideológicas de las antiguas costumbres funerarias mayas.

En sus conclusiones sintetiza sus hallazgos concentrados en la disposición del cadáver y conceptos y sentimientos respecto a la muerte. En cuanto al pri- 


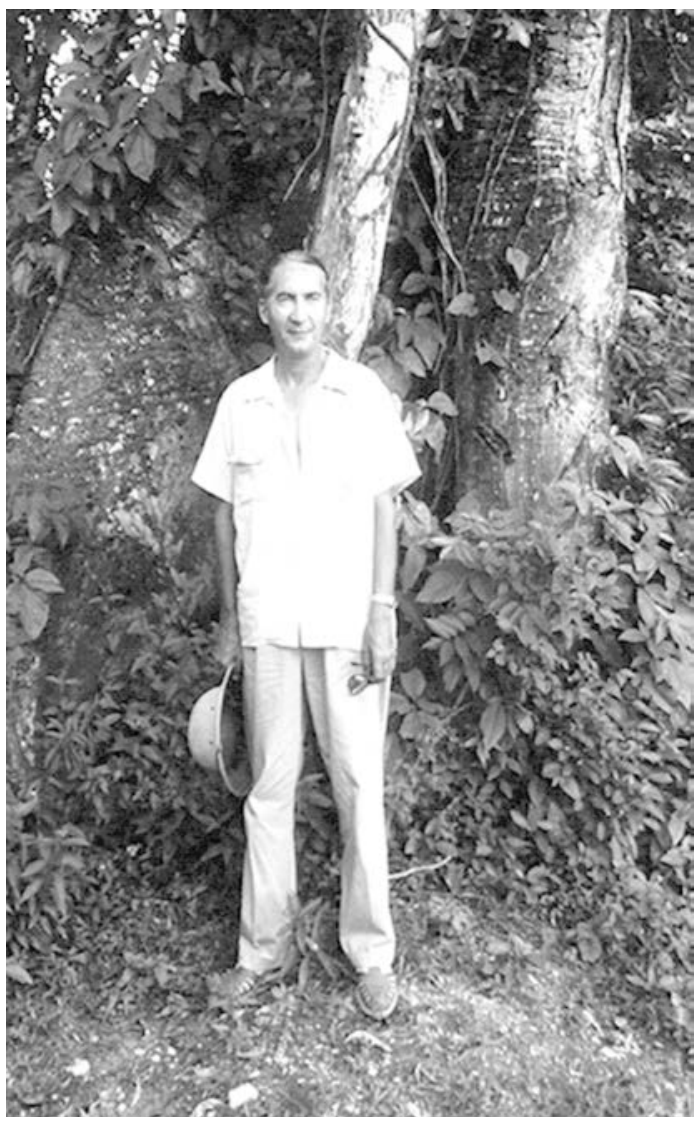

Figura 5. Alberto Ruz en Palenque. Archivo Miguel Covarrubias, Universidad de las Américas, Dirección General de Bibliotecas, Arquitectura Maya I (Dibujos, Fotografías y Recortes).

Fotografía de Rosa Covarrubias.

mer aspecto, los mayas, apunta, no muestran especificidad alguna, sino que los patrones universales están siempre representados entre ellos (Ruz, 1968a: 111). Con relación al tema del pensamiento, la creencia maya es que al fallecimiento de cualquier hombre sobreviven carne y espíritu, aunque se separan ambas partes, con los cuales la comunidad debe vincularse de una manera que sea gratificante para el difunto. Y según el rango del fallecido será la fuerza sagrada desplegada en la comunidad.

Por otro lado, Ruz acentúa entre los mayas la creencia en la resurrección, aunque juega un tanto con el concepto de transformación. Explica: "El concepto fundamental del mundo precortesiano es la inmortalidad, la indestructibilidad de la fuerza vital, la transformación según el ritmo invariable de los astros y las estaciones" (Ruz, 1968a: 264). 
El tema de la muerte ha sido un asunto constante en las investigaciones sobre la cultura maya y actualmente, tanto antropólogos físicos, como arqueólogos y antropólogos sociales, así como historiadores, han abordado el tema citando frecuentemente la obra de Alberto Ruz, no sólo como el antecedente clásico de la temática, sino en ocasiones adscribiéndose a algunas de sus interpretaciones, aunque aquella de la resurrección ya no tiene seguidores.

A la luz de lo antes expuesto, consideramos un buen colofón los conceptos que Fernando Benítez (Uno más Uno, 29 de agosto de 1979) dedicó a Alberto Ruz en su obituario: "Tenía la curiosidad de los grandes arqueólogos, la inteligencia que descifra los enigmas, el amor al pasado y la constancia para imponerse a las hostilidades de una masa ciega devoradora de hombres y civilizaciones".
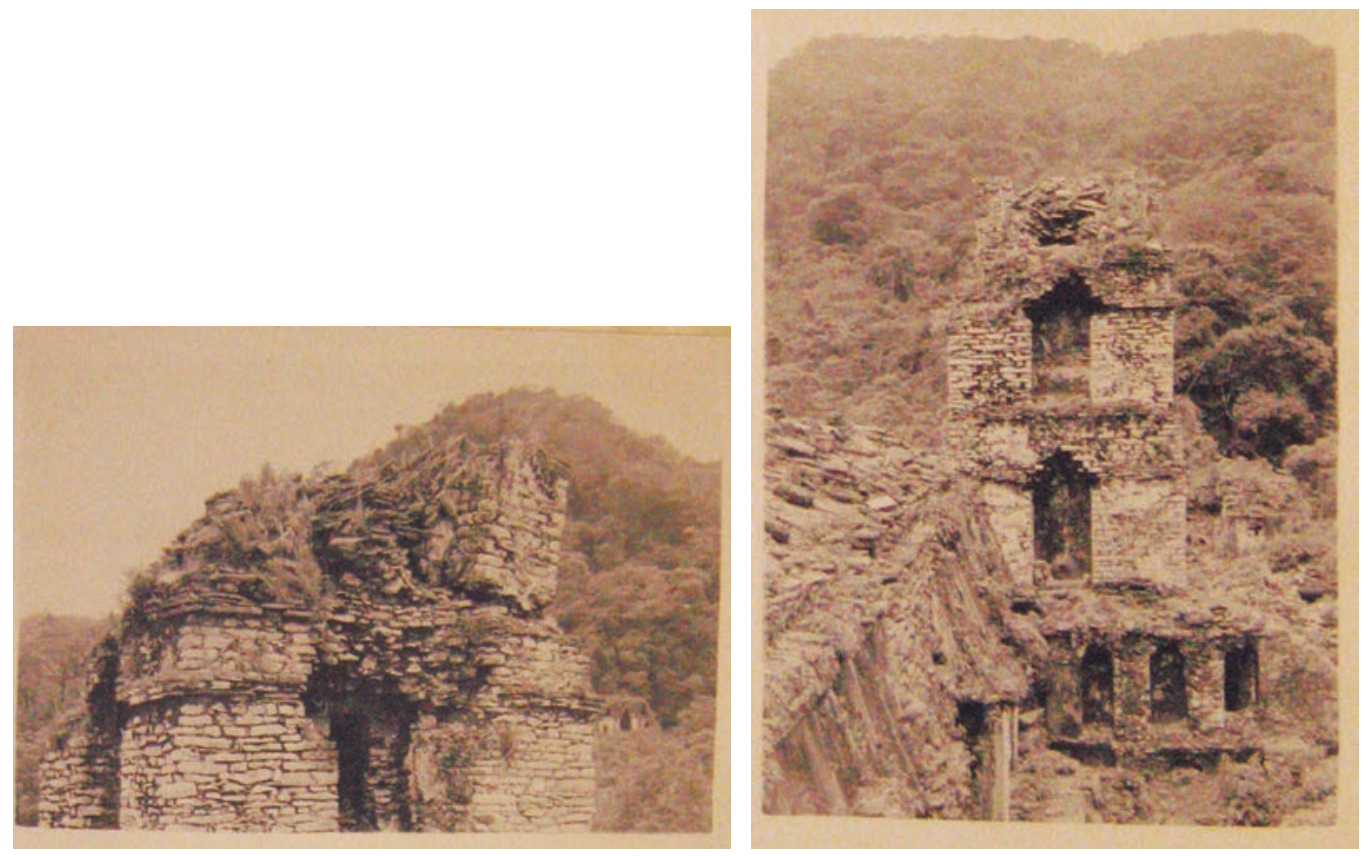

Figura 6. Fotografías de la temporada de campo de 1953, durante la cual se reconstruyó la torre del Palacio (Ruz, 1958: 75). 


\section{BIBLIOGRAFÍA}

Andrews, Anthony

"Entrevista”, conducida por Ana Luisa Izquierdo el 24 de abril de 2014.

Andrews IV, Edward

1971 "La Costa de Campeche en los Tiempos Prehispánicos. Prospección Cerámica y Bosquejo Histórico de Alberto Ruz Lhuillier", American Anthropologist, 73 (2): 424-425.

1958 "Diario manuscrito", inédito (cortesía de Anthony Andrews).

Anónimo

1953 “Pyramid’s Secret”, Life Magazine, 34: 70-74.

Argenteri, Letizia

2003 Tina Modotti: Between Art and Revolution. New Haven: Yale University Press.

Benítez, Fernando

1979 "Obituario", Uno más Uno, 29 de agosto.

Black, Stephens

1990 "Field Methods and Methodologies in Lowland Maya Archaeology", Ph. D. Thesis of Anthropology. Cambridge: Harvard University.

Boyer, Ernest Leroy

1965 "Carta de Alberto Ruz L.”, 6 de enero, Archivo Rockefeller, Serie de Proyectos, folio 865 , Palenque.

Castro, Rosa

1958 “Alberto Ruz", Archivo personal de Alberto Ruz Buenfil (inédito).

Caplow, Deborah y Leopoldo Méndez

2007 Revolutionary Art and the Mexican Print. Austin: University of Texas Press.

Coe, Michael

1992 Breaking the Maya Code. New York: Thames \& Hudson.

Covarrubias, Rosa

1954 "Carta a Nelson Rockefeller", 31 de marzo, folio 433, Colección familiar, Archivo Rockefeller.

Dávalos Hurtado, Eusebio y Arturo Romano Pacheco

1978 "Estudio preliminar de los restos osteológicos encontrados en la tumba del Templo de las Inscripciones, Palenque", El Templo de las Inscripciones, Palenque, pp. 253-254, Alberto Ruz Lhuillier (ed.). México: Instituto Nacional de Antropología e Historia (Colección Científica, 7). 
Ekholm, Gordon F.

1952 "Paralelos significativos en el arte simbólico del sur de Asia y Mesoamérica", Tlatoani, I (5-6): 29-35.

1953 "A Possible Focus of Asiatic Influence in the Late Classic Cultures of Mesoamerica", Asia and North America, Transpacific Contacts, pp. 72-89, M. W. Smith (ed.). Salt Lake City: University of Utah Press (Memories of the Society for American Archaeology, 9).

Estrade, Paul

2001 Solidaridad con Cuba libre, 1895-1890: La impresionante labor del Dr. Betances en París. Puerto Rico: Editorial de la Universidad de Puerto Rico.

Guiteras, Calixta

1961 Perils of the Soul. The World View of Tzotzil Indian, Sol Tax (pról.). New York: The Free Press of Glencoe, Inc.

1965 Los peligros del alma. Visión del mundo de un tzotzil. México: Fondo de Cultura Económica.

Heine-Geldern, Robert von and Gordon F.

1951 "Significant Parallels in the Symbolic Arts of Southern Asia and Middle America", Civilizations of Ancient America: Selected Papers of the XXIXth International Congress of Americas, pp. 299-309, Wendell C. Bennett (introd.), Sol Tax (ed.). Chicago: University of Chicago Press.

Hilton, Ronald

1945 Who's who in Latin America: a Biographical Dictionary of Notable Men and Women of Latin America, 3 ed., Part 1. Stanford: Stanford University Press.

Hopkins, Nicolas

1967 "Summary of the First Seminar for the Study of Maya Writing", Latin American Research Review, 2 (2): 91-94.

Izquierdo y de la Cueva, Ana Luisa

1987 Alberto Ruz frente al pasado de los mayas. México: Secretaría de Educación Pública (Cien de México).

Kowaleski, Jeff y Cynthia Kristan-Graham

2007 Twin Tollans. Chichén Itzá, Tula, and the Epiclassic to Early Postclassic Mesoamerican Worlds. Washington: Dumbarton Oaks.

Kubler, George

1961 "Chichén Itzá y Tula", Estudios de Cultura Maya, I: 47-80.

1962 "Réplica del doctor Kubler al trabajo de Alberto Ruz que antecede”, Estudios de Cultura Maya, II: 221-223.

Landa, fray Diego de

1938 Relación de las cosas de Yucatán, Héctor Pérez Martínez (introd., notas y ed.). México: Editorial P. Robredo. 
Leuchsenring, Emilio Roig de

1979 Historia de la enmienda Platt: una interpretación de la realidad cubana. La Habana: Editorial de Ciencias Sociales.

Ley sobre protección y conservación de monumentos arqueológicos e históricos, poblaciones típicas y lugares de belleza natural y su reglamento

1934 México: Secretaría de Educación Pública y Departamento de Monumentos Artísticos, Arqueológicos e Históricos.

Manrique Castañeda, Leonardo

1968 "El primer seminario internacional sobre la escritura maya: resultados y perspectivas", Estudios de Cultura Maya, VII: 371-381.

Marquina, Ignacio

1949 “Carta”, 1 de marzo de 1949, Récords del Instituto de Estudios Andinos del American Museum of Natural History. División de Antropología, Folder B, Palenque, Proyecto Ruz, 1958-1955.

Morley, Sylvanus Grisworld

1915 An Introduction to the Study of Maya Hieroglyphs. Washington: Smithsonian Institution for American Ethnology (Bulletin, 57).

1945 "Historia general de los antiguos mayas", Enciclopedia Yucatanense, vol. 2, pp. 5-52, Carlos A. Echánove Trujillo (ed.). México: Edición Oficial del Gobierno de Yucatán.

1942 Historia antigua de Yucatán: el nuevo imperio. Washington: Institución Carnegie de Washington.

1946 The Ancient Maya. California: Stanford University Press.

1947 Los antiguos mayas, Adrián Recinos (trad.). México: Fondo de Cultura Económica.

Ochoa, Lorenzo y Ernesto Vargas

1979 "El colapso maya. Los chontales y Xicalango", Estudios de Cultura Maya, XII: 61-91.

Pérez Martínez, Héctor

1943 Catálogo de documentos para la historia de Yucatán y Campeche, que se hallan en diversos archivos y bibliotecas de México y del extranjero. Campeche: Museo Arqueológico, Histórico y Etnográfico de Campeche.

Pitman, Thea

2007 "Identidad nacional y feminismo en el periodismo de mujeres: el caso de Elvira Vargas”, Literatura Mexicana, XVIII (1): 131-143.

Rockefeller, Nelson. A.

1947 "Carta a Rosa Covarrubias", 29 de septiembre, folio 90-867, Archivo Rockefeller, Serie de Proyectos, Palenque.

1949 “Carta a A. V. Kidder”, 21 de diciembre de 1947, Récords del Instituto de Estudios Andinos del American Museum of Natural History, División de Antropología, Proyectos Rockefeller: Palenque. 
Roys, Ralph

1943 The Indian Background of Colonial Yucatan. Washington: Carnegie Institution (Publication 548).

Ruz Buenfil, Alberto

2010 Transcripción de la entrevista realizada por Elaine Schele, México.

Ruz Lhuillier, Alberto

1942 "Carta al Dr. J. Alden Mason”, 28 de Julio. Mss. B.M. 384. Series 1, Correspondencia, American Philosophical Society, Papeles de John Alden Mason, 1926-1967.

1944 "Sentido humano de la Arqueología”, El Reproductor Campechano, 1 (4): 113-117.

1945 “Arqueología maya: Trayectoria y meta”, Cuadernos Americanos, 22 (4): 139155.

1948 “The Ancient Maya de Sylvanus G. Morley”, Acta Americana, VI: 78-88.

1949 "Exploraciones arqueológicas en Palenque, Chiapas: Informe de la Temporada del Proyecto Palenque de 1949”, pp. 1-73, vol. C. New York: American Museum of Natural History.

1950 "Universalidad, singularidad y pluralidad del arte maya”, México en el Arte, vol. 9, pp. 10-24. México: Instituto Nacional de Bellas Artes.

1952a "Exploraciones arqueológicas en Palenque: 1951", Anales del Instituto Nacional de Antropología e Historia, 6a época, V (33): 47-66.

1952b "Estudio de la cripta del Templo de las Inscripciones en Palenque", Tlatoani, 3-4: 118-120.

1954 "Exploraciones arqueológicas en Palenque: 1952”, Anales del Instituto Nacional de Antropología e Historia, 6a época, VI (34): 79-106.

1957 La civilización de los antiguos mayas, Felipe Martínez Arango (presentación). Santiago de Cuba: Universidad de Oriente, Departamento de Extensión y Relaciones Culturales.

1961 "El Seminario de Cultura Maya”, Estudios de Cultura Maya, I: 7-11.

1963 La civilización de los antiguos mayas, Felipe Mártinez Arango (pról.). México: Instituto Nacional de Antropología e Historia (Serie Historia, 10).

1964a La civilisation des anciens mayas, G. Stresser-Pean (pról.). México: Instituto Nacional de Antropología e Historia (Serie Historia, 24).

1964b "¿Aristocracia o democracia entre los antiguos mayas?, Anales de Antropología, I: 63-75.

1964c “Influencias mexicanas sobre los mayas", Desarrollo cultural de los mayas, pp. 195-227, Evon Z. Vogt y Alberto Ruz (eds.). México: Universidad Nacional Autónoma de México, Facultad de Filosofía y Letras, Seminario de Cultura Maya.

1964d "Actividades del Seminario de Cultura Maya”, Estudios de Cultura Maya, IV: 375-377.

1966 "Desciframiento de la escritura maya: historia, resultados y perspectivas", Suma Anthropologica, Homenaje a Roberto J. Weitlaner, pp. 173-175, Antonio Pompa y Pompa (ed.). México: Instituto Nacional de Antropología.

1968a Costumbres funerarias de los antiguos mayas. México: Universidad Nacional Autónoma de México, Facultad de Filosofía y Letras, Seminario de Cultura Maya.

1968b "Prólogo", Estudios de Cultura Maya, VII: 23-32. 
1968c "Destrucción y saqueo en las zonas arqueológicas mayas", conferencia presentada en el Seminario de Cultura Mexicana. Documento inédito de la Biblioteca Americana Karl Herbert Mayer. Graz: Austria.

1969 La Costa de Campeche en los tiempos prehispánicos: Prospección cerámica y bosquejo histórico. México: Instituto Nacional de Antropología e Historia (Serie de Investigaciones, 18).

1970a La civilización de los antiguos mayas, Eric J. Thompson (pról.). México, Instituto Nacional de Antropología e Historia (Serie Historia, 24).

1970b La civilisation des anciens mayas, $2^{\mathrm{a}}$ ed. México: Instituto Nacional de Antropología e Historia (Serie Historia, 24).

1973a “Alfonso Caso Andrade (1896-1970)", Estudios de Cultura Maya, IX: 365-370.

1973b El Templo de las Inscripciones, Palenque. México: Instituto Nacional de Antropología e Historia (Colección Científica, 7).

1973c "Edward Wyllys Andrews IV, 1916-1972”, Estudios de Cultura Maya, IX: 381391.

1976 "Nuevas interpretaciones de la inscripción jeroglífica en el sarcófago del Templo de las Inscripciones", Art, Iconography and Dynastic History of Palenque, pp. 87-93, Merle Greene Robertson (ed.). California, Pebble Beach: The Robert Louis Stevenson School y Pre-Colombian Art Research.

1976 "Semblanza de John Eric Sidney Thompson (1898-1975)", Estudios de Cultura -1977 Maya, X: 317-335.

1977 “Gerontocracy at Palenque?", Social Process in Maya Prehistory: Studies in honor of Sir Eric Thompson, pp. 287-295, N. Hammond (ed.). Londres: Academic Press.

1979a Dirección General de Personal. Expediente inédito.

1979b Chichén Itzá en la historia y en el arte. Pedro Ramírez Vásquez (pról.). México: Editora del Sureste.

1981a El pueblo maya. México: Salvat Mexicana de Ediciones y Fundación Cultural [1982] San Jerónimo Lídice.

1981b "Un modo de producción tributario en el área maya", Estudios de Cultura Maya, XIII: 37-43.

Salazar Ortegón, Ponciano

1961 "Informe de labores", Archivo Técnico del Instituto Nacional de Antropología e Historia, Departamento de Monumentos Prehispánicos, 1920-1950, $\mathrm{B} / 101.1(72-64) 1$.

Schávelzon, Daniel

1990 La conservación del patrimonio cultural en América Latina. Restauración de edificios prehispánicos en Mesoamérica: 1750-1980. Buenos Aires: Universidad de Buenos Aires, Facultad de Arquitectura, Instituto de Arte Americano e Investigaciones Estéticas y The Getty Grant Program.

Schele, Elaine Day

2012 "The Untold Story of Alberto Ruz and his Archaeological Excavations at Palenque, México: A Micro and Macrohistorical Approach”, tesis de doctorado en Estudios Latinoamericanos. Austin: Universidad de Texas en Austin. 
Suchlicki, Jaime

1968 "Stirrings of Cuban Nationalism: The Student Generation of 1930", Journal of Inter-American Studies, 10 (3): 350-368.

Tabares del Real, José A.

1973 Guiteras. Nuestra historia. La Habana: Instituto Cubano del Libro.

Tiesler, Vera y Andrea Cucina (eds.)

2006 Janaab' Pakal of Palenque: Reconstructing the Life and Death of a Maya Ruler. Tucson: University of Arizona Press.

Vogt, Evon Z.

1961 "Some aspects of Zinacantan Settlement Patterns and Ceremonial Organization”, Estudios de Cultura Maya, I: 131-145.

Vogt, Evon Z. y Alberto Ruz (eds.)

1964 Desarrollo cultural de los mayas. México: Universidad Nacional Autónoma de México, Facultad de Filosofía y Letras, Seminario de Cultura Maya.

Willey R., Gordon

1956 "The Structure of Ancient Maya Society: Evidence from the Southern Lowlands", American Anthropologist, 58 (5): 777-782. 